\title{
Produção e qualidade da videira 'Superior Seedless' sob restrição hídrica na fase de maturação
}

\author{
Lígia Borges Marinho(1), José Julio Vilar Rodrigues(1), José Monteiro Soares ${ }^{(2)}$, \\ Maria Auxiliadora Coelho de Lima ${ }^{(2)}$, Magna Soelma Beserra de Moura(2), \\ Elieth Oliveira Brandão(2), Thieres George Freire da Silva ${ }^{(3)}$ e Marcelo Calgaro(2)
}

\begin{abstract}
(1)Universidade Federal Rural de Pernambuco, Departamento de Tecnologia Rural, CEP 52171-900 Recife, PE. E-mail: ligia.bmarinho@gmail.com, juba.vilar@oi.com.br (2)Embrapa Semiárido, Caixa Postal 23, CEP 56310-000 Petrolina, PE. E-mail: monteiro@cpatsa.embrapa.br, magna@cpatsa.embrapa.br, maclima@cpatsa.embrapa.br, elieth.brandao@cpatsa.embrapa.br, marcelo.calgaro@cpatsa.embrapa.br ${ }^{(3)}$ Universidade Federal Rural de Pernambuco, Unidade Acadêmica de Serra Talhada, CEP 56900-000 Serra Talhada, PE. E-mail: thieres@uast.ufrpe.br
\end{abstract}

\begin{abstract}
Resumo - O objetivo deste trabalho foi avaliar o efeito das condições de deficit hídrico, na fase de maturação da uva, sobre a produção e qualidade da uva 'Superior Seedless' entre julho e novembro de 2007. O experimento foi realizado em delineamento de blocos ao acaso, com quatro repetições, em arranjo fatorial $(3 \times 3)+1$ : três épocas de alteração da aplicação das lâminas de irrigação (21, 13 e 5 dias antes da colheita); três lâminas de irrigação (100, 50 e $0 \%$ da evapotranspiração da cultura); e um tratamento controle (manejo de irrigação adotado pelo produtor). As épocas de irrigação e as lâminas de irrigação utilizadas influenciaram a firmeza das bagas e a acidez titulável. A interrupção da irrigação, aos 13 ou 21 dias antes da colheita, resultou em produtividade, qualidade de frutos e eficiência do uso da água semelhante às obtidas pelo produtor, assim, pode ser adotada para economia da água de irrigação na Região do Submédio do Vale do São Francisco.
\end{abstract}

Termos para indexação: Vitis vinifera, estresse hídrico, qualidade da uva, rendimento.

\section{Production and quality of 'Superior Seedless' grapes under irrigation restrictions during berry maturation}

\begin{abstract}
The objective this work was to evaluate the effect of water deficit conditions, during the maturation phase of grapes, on the production and quality of the 'Superior Seedless', between July and November of 2007. The experiment was carried out in a randomized block design, with four replicates, in a $(3 \times 3)+1$ factorial arrangement: three times of alteration of the irrigation depths (21, 13 e 5 days before harvest); three irrigation depths (100, 50 e $0 \%$ of crop evapotranspiration); and a control treatment, which was the producer's irrigation management scheme. Irrigation timing and depth influenced berry firmness and titrable acidity. The management with cut-off irrigation depths at 13 or 21 days before harvesting and the control had the same yield, grape quality and water use efficiency, and may be adopted to save water for irrigation in the São Francisco Valley region.
\end{abstract}

Index terms: Vitis vinifera, water stress, grape quality, yield.

\section{Introdução}

A 'Superior Seedless', também conhecida por 'Sugraone' (Vitis vinifera L.), é a principal cultivar de uva sem sementes produzida no Submédio do Vale do São Francisco (Grangeiro et al., 2002). Nas condições desta região vinícola, com clima semiárido, o uso de irrigação é indispensável.

Em razão da escassez dos recursos hídricos e do alto custo dos insumos, cada vez mais, têm-se buscado alternativas que racionalizem o uso de água na irrigação, a fim de aumentar a competitividade desta região em relação a outras tradicionalmente produtoras de uva.

No Submédio do Vale do São Francisco, os viticultores não têm empregado padrões adequados de deficit hídrico, na fase final de maturação da uva de mesa. Estratégias de imposição do deficit hídrico só devem ser adotadas se a economia de água não tiver impacto negativo na produtividade e na qualidade da uva (Netzer et al., 2009). 
Segundo Ávila Netto et al. (2000), a restrição hídrica durante as duas primeiras fases de crescimento das bagas pode reduzir o tamanho dos frutos e atrasar o seu amadurecimento. Serman et al. (2004), em experimento com a cultivar Apirênia Superior Seedless, irrigada sob diferentes percentagens da evapotranspiração, verificaram diminuição do número de cachos comercializáveis, nos tratamentos com deficit hídrico, apesar de não terem observado diferenças significativas nos sólidos solúveis. No entanto, no Submédio do Vale do São Francisco, Bassoi et al. (1999) avaliaram a suspensão total da irrigação na cultivar Itália, num período de até 30 dias antes da colheita, e não constataram redução significativa na qualidade ou na produtividade da uva. De acordo com Ferreyra et al. (2006), a aplicação de deficit hídrico à cultivar Crimson Seedless proporcionou diferenças significativas apenas quanto à produtividade, sobretudo a partir do segundo ciclo de cultivo, possivelmente em razão dos efeitos cumulativos dos diferentes anos de restrição de irrigação.

O objetivo deste trabalho foi avaliar o efeito da irrigação deficitária no período de maturação sobre a produção e a qualidade da cultivar de uva de mesa Superior Seedless, no Submédio do Vale do São Francisco.

\section{Material e Métodos}

O experimento foi realizado na Fazenda Agrobrás Tropical do Brasil S/A, no Município de Casa Nova, BA (9¹9'36"S, 4047'53"W e a 399 m de altitude), na região semiárida do Submédio do Vale do São Francisco, de julho a novembro de 2007. O clima local é do tipo BSwh, segundo Köppen, com estação chuvosa limitada aos meses de janeiro a abril, e precipitações escassas de distribuição irregular, com média anual em torno de 400 mm (Hargreaves, 1974; Reedy \& Amorim Neto, 1993). O solo da área experimental é classificado como Argissolo Vermelho-Amarelo (Embrapa Semiárido, 2007).

Utilizou-se a cultivar Superior Seedless (Vitis vinifera $\mathrm{L}$.), enxertada sobre a cultivar $\mathrm{SO} 4$, com quatro anos de idade e segundo ciclo de produção, cultivada no espaçamento de $3,5 \mathrm{~m}$ x $2,0 \mathrm{~m}$ e conduzida no sistema de latada.

O delineamento experimental foi blocos ao acaso com quatro repetições, em arranjo fatorial $(3 \times 3)+1$ : três épocas (E) de alteração da aplicação de diferentes lâminas de irrigação, em relação à colheita - 21 (E21), 13 (E13) e 5 (E5) dias antes da colheita (DAC) -; três lâminas de irrigação (L) - 100\% (L100), 50\% (L50) e $0 \%$ (L0) da evapotranspiração da cultura (Etc) -; mais um tratamento controle, correspondente ao manejo adotado pelo produtor (LP), com irrigação com cerca de 95\% da Etc, até um dia antes da colheita (L95-E01); quando foi totalmente suspensa.

No talhão selecionado, foi escolhida uma área de $2.240 \mathrm{~m}^{2}(28 \times 80 \mathrm{~m})$, constituída por oito fileiras com 40 plantas cada, no total de 320 plantas, onde foram distribuídos os blocos. Em cada bloco, havia quatro linhas com seis plantas por tratamento, em que foram consideradas as quatro plantas centrais como unidades experimentais, no total de 160 plantas úteis. As lâminas de irrigação, até os $21 \mathrm{DAC}$, foram quantificadas pelo produtor com base em dados de evapotranspiração de referência (ETo), provenientes de uma estação meteorológica automática situada a aproximadamente $2 \mathrm{~km}$ da área experimental, e com base nos dados do coeficiente de cultura $(\mathrm{Kc})$ definidos para a fase de maturação $(0,8$ para o período entre 85 e 92 dias após a poda - DAP -; 0,6, entre 93 e 100 DAP; e 0,4 entre 101 e 104 DAP) conforme Soares \& Costa (2000). Para estimar a Eto, foi utilizada a equação de Penman-Montheith parametrizada pela FAO (Allen et al., 1998).

O sistema de irrigação utilizado foi o gotejamento, com uma linha lateral por fileira de plantas, e emissores autocompensantes espaçados em $30 \mathrm{~cm}$. A frequência de irrigação foi diária, exceto aos domingos. Realizou-se a avaliação do coeficiente de uniformidade de distribuição de água, conforme Karmeli \& Keller (1975), com valor médio de $94,4 \%$, e vazão média de $2,89 \mathrm{~L}$ por hora. Diariamente, realizou-se o monitoramento do potencial mátrico do solo, por meio de tensiômetros instalados a 20 e $40 \mathrm{~cm}$ de profundidade. A partir da curva de retenção da água no solo (Marinho, 2008), os valores em umidade volumétrica $(\theta)$ foram convertidos em base de $\mathrm{cm}^{3} \mathrm{~cm}^{-3}$.

A poda, realizada no dia $11 / 7 / 2007$, foi do tipo mista com varas e esporões. Foram mantidas as varas que tinham de 10 a 16 gemas e os esporões com duas ou três gemas. Logo após a poda, os ramos foram pulverizados com calcianamina hidrogenada (Dormex, formulada pela Basf, fabricada pela AlzChem Trostberg $\mathrm{GmbH}$, Trostberg, Alemanha), à concentração $5 \% \mathrm{v} / \mathrm{v}$ 
para quebra de dormência das gemas e uniformização da brotação. $O$ índice de fertilidade real de gemas foi obtido pela divisão do número total de cachos pelo número total de gemas (varas e esporões), conforme Leão \& Silva (2003). Esta avaliação foi realizada em 16 plantas por tratamento, antes da desbrota dos ramos.

Aos 2, 5, 9 e 14 DAC, foram feitas amostragens de seis bagas por cacho, de cada parcela experimental. Após a coleta, as amostras foram armazenadas em isopor com gelo e transportadas para o Laboratório de Pós-Colheita da Embrapa Semiárido, em Petrolina, PE, onde foram realizadas as seguintes análises químicas: teor de sólidos solúveis (SS), por meio de refratômetro digital (Hanna, Modelo - HI - 96801, Milliminas Limitada, Belo Horizonte, Brasil); ácidez titulável (AT), por meio da titulação da polpa das bagas com $\mathrm{NaOH} 0,1 \mathrm{~N}$, expresso em gramas de ácido tartárico por $100 \mathrm{~mL}$ de suco, conforme Pregnolatto \& Pregnolatto (1985); relação SS/AT.

Logo após a colheita da uva, no dia 24/10/2007 (aos 105 DAP), em conformidade com a programação da fazenda, quantificou-se: o diâmetro de baga, com paquímetro digital (Stainless Hardened, VTC, Ribeirão Preto, Brasil), em oito cachos por tratamento e três bagas por cacho (uma baga localizada no ápice, uma no meio e outra na extremidade inferior do cacho), no total de 240 amostragens; o peso médio de cachos (em g), por meio de balança digital (capacidade de 6.100 g, sensibilidade de $0,1 \mathrm{~g}$, Marte, Brasil); o número total de cachos por planta; o peso total de cachos por planta $(\mathrm{em} \mathrm{kg})$; e a produtividade $\left(\mathrm{Mg} \mathrm{ha}^{-1}\right)$. Nesse momento, também foram separados quatro cachos representativos de cada parcela, tendo-se utilizado 16 plantas por tratamento, dos quais foram avaliadas cinco bagas cada quanto à firmeza da polpa, sólidos solúveis, acidez titulável e relação SS/AT. A firmeza da polpa da baga foi determinada com um penetrômetro (TR, Modelo - FT 327, Gold Lab, Ribeirão Preto, Brasil).

Por meio da relação entre a quantidade total de uva produzida e a lâmina de água aplicada, acumulada entre a poda e a colheita, calculou-se a eficiência de uso da água (EUA) (Doorenbos \& Kassam, 1994).

Os dados foram submetidos à análise de variância, para se determinar a interação entre os fatores e comparar as médias conforme Yassin et al. (2002). As médias dos tratamentos foram comparadas pelo teste de Duncan, a 5\% de probabilidade. Por meio de teste $\mathrm{F}(\mathrm{p}<0,05)$, obteve-se a significância do contraste, pela comparação da média dos tratamentos do fatorial com o controle e, quando significativas, foram comparadas as médias do tratamento adicional às médias dos fatoriais, pelo teste de Dunnett, a 5\% de probabilidade. Utilizou-se o programa SAS versão 9.0 for Windows (SAS Institute, 2002).

\section{Resultados e Discussão}

Durante o período experimental, a temperatura média do ar oscilou em torno de $25,3 \pm 1,57^{\circ} \mathrm{C}$, com umidade relativa média de $56,5 \pm 6,62 \%$, e com evapotranspiração de referência média de $5,37 \pm 0,88 \mathrm{~mm}$ por dia.

As lâminas aplicadas, acumuladas na fase de maturação e no ciclo produtivo da uva 'Superior Seedless', e o deficit de irrigação, em relação ao tratamento LP, podem ser observadas na Tabela 1.

A diminuição de aplicação de água, na fase de maturação da uva nas E21-L0, E21-L50 e E13-L0, em

Tabela 1. Lâminas acumuladas de irrigação, durante a fase de maturação e o ciclo produtivo completo da cultivar de videira Superior Seedless.

\begin{tabular}{lcc}
\hline Diferenciação do manejo da água ${ }^{(1)}$ & Fase de maturação $(\mathrm{mm})$ & Ciclo completo $(\mathrm{mm})$ \\
\hline E21-L100 & 61,5 & 399,3 \\
E21-L50 & 32,2 & 366,7 \\
E21-L0 & 3,0 & 334,1 \\
E13-L100 & 61,6 & 399,4 \\
E13-L50 & 48,7 & 385,0 \\
E13-L0 & 32,8 & 367,3 \\
E5-L100 & 58,2 & 395,5 \\
E5-L50 & 54,7 & 391,7 \\
E5-L0 & 51,3 & 387,9 \\
LP & 56,4 & 393,5 \\
(1)E, época de alteração da lâmina de irrigação, em relação à colheita: E5, 5 dias; E13, 13 dias e E21, 21 dias antes da colheita; L, lâminas de irrigação \\
aplicadas: L0, L50 e L100, lâminas de 0, 50 e 100\% da evapotranspiração da cultura (Etc), respectivamente; LP, lâmina do produtor: irrigação com cerca de \\
95\% da Etc, até um dia antes da colheita (E1-L95).
\end{tabular}


relação ao tratamento controle (LP), ocasionou deficit de irrigação, respectivamente, de 19,5, 8,9 e 8,7\%, que resultou na economia de água de 53,4, 24,1 e 23,50 mm. Esta economia é representativa sob o ponto de vista econômico. As lâminas aplicadas durante todo o ciclo produtivo da videira variaram de 334,14 a $399,36 \mathrm{~mm}$ e foram semelhantes às encontradas por Ávila Netto et al. (2000) (333,6 mm), em estudo no Submédio do São Francisco, com a cultivar Itália, sob regime de deficit hídrico. No Chile, Ferreyra et al. (2006) obtiveram lâmina média aplicada de $376,90 \mathrm{~mm}$ para videiras 'Crimson Seedless' irrigadas com $50 \%$ da ETc, durante todo o ciclo produtivo. Lâminas maiores (entre 649 e $1.060 \mathrm{~mm}$ por ano) foram determinadas para a videira 'Superior Seedless', por Serman et al. (2004), que trabalharam com a aplicação de deficit hídrico com base na ETc, na Argentina. Entretanto, vale salientar que o ciclo da cultura tem maior duração na Argentina e no Chile do que no Brasil, em razão das diferentes condições climáticas.

O conteúdo de água no solo, durante o ciclo produtivo da videira 'Superior Seedless', está apresentado na Figura 1. Até 84 DAP, a umidade volumétrica $\theta\left(\mathrm{cm}^{3} \mathrm{~cm}^{-3}\right)$ variou pouco na camada do solo de 0 a $20 \mathrm{~cm}$ de profundidade, com valores médios de $0,244 \mathrm{~cm}^{3} \mathrm{~cm}^{-3}$. Contudo, depois dos 89 DAP, o tratamento E21-L0 teve conteúdo de água no solo de $0,129 \mathrm{~cm}^{3} \mathrm{~cm}^{-3}$, próximo ao ponto de murcha $\left(0,117 \mathrm{~cm}^{3} \mathrm{~cm}^{-3}\right)$ e, nos demais tratamentos, os valores de $\theta$ foram superiores a $0,150 \mathrm{~cm}^{3} \mathrm{~cm}^{-3}$. Esses resultados indicam que após o começo da alteração de aplicação das lâminas, as plantas estavam expostas à umidade do solo inferior à capacidade de campo (CC), como era previsto. Nos tratamentos E21-L0 e E5-L100, a umidade do solo variou entre 44,6 e $80,15 \%$ da CC e entre 55,8 a $87,3 \%$ da CC, respectivamente. Aos 93 DAP, o tratamento E13-L0 registrou o mínimo de água no solo. Valores semelhantes de umidade do solo (entre 59 e $83 \%$ CC) foram observados em tratamento com lâmina calculada a $50 \%$ da Etc, por Ferreyra et al. (2006), que trabalharam com uva 'Crimson Seedless', em parreiral espanhol.

Não houve diferenças significativas entre os fatoriais nos índices de fertilidade real de gemas (Tabela 2); entretanto, observou-se diferença entre as médias dos fatoriais e o tratamento controle (LP), pelo teste F. Os valores de fertilidade de gema de todos os tratamentos foram 10\% superiores àqueles obtidos para a cultivar Superior
Seedless, por Leão \& Silva (2003). Essa superioridade, possivelmente, é resultante de que, no presente trabalho, as podas foram mais longas e, consequentemente, analisaram-se até 16 gemas nas varas.

Não houve diferença significativa para os sólidos solúveis (SS), em função das épocas de alteração da irrigação em relação à colheita e das lâminas, nas datas amostradas, ou das diferenças das médias dos fatoriais comparadas ao tratamento controle (LP) (Tabela 3). Porém, ao se considerarem as datas de amostragem (Tabela 4), houve aumento progressivo de SS, que alcançou os maiores valores aos 2 e 5 DAC, e os menores aos 9 e 14 DAC. Estes resultados indicam que esse incremento de SS pode ser atribuído à modificação metabólica na translocação do açúcar, que foi acumulado nas bagas, na fase de maturação. Os sólidos solúveis tendem a aumentar acentuadamente com o crescimento da baga até alcançar um ponto de equilíbrio, com valores que dependem da cultivar, tamanho da baga, produção por planta e das condições climáticas durante a maturação da baga. O teor de sólidos solúveis tende a aumentar com a maturação da baga, em consequência da degradação dos polissacarídeos (Chitarra \& Chitarra, 1990), e do conteúdo de água no solo.

$\mathrm{Na}$ L0, houve diferenças significativas em acidez titulável (AT) (Tabela 3) apenas na amostragem aos 2 DAC na E21, em comparação com a E13 e E5; ao se considerarem as épocas de diferenciação, observou-se que a lâmina L50 apresentou maior acidez titulável na E5, em comparação L0 e L100. Valores de acidez titulável altos são benéficos sob o ponto de vista microbiológico, pois inibem o crescimento de patógenos nocivos à saúde humana, sem comprometer a qualidade sensorial do produto (Mattiuz et al., 2004). Os resultados do presente trabalho estão de acordo com essa afirmação para os parâmetros produtivos, em que o tratamento E5 mostrou-se influenciado pelas alterações da irrigação. Com isso, entende-se que ao ocorrer deficit de irrigação antes dessa época, a planta se ajusta e não permite reduções significativas dos seus atributos produtivos e de AT e SS/AT, antes da colheita, e a alteração da irrigação às épocas E13 e E21 pode, então, ser adotada com vistas à economia de água.

Analisando-se os valores médios de AT, em relação às datas de amostragem (Tabela 4), verifica-se que são inversos aos de SS, pois são inicialmente altos, diminuem aproximadamente $20 \%$ a cada dia com a evolução da maturação e atingem valores máximos e mínimos aos 14 e 2 DAC. A redução da AT pode estar 
relacionada ao fato de os ácidos tartárico e málico serem sintetizados pelas folhas e pelas bagas verdes que, no início da maturação apresentam elevado teor de AT. Com a evolução da maturação, a demanda por energia aumenta e, muitas vezes, os ácidos são utilizados como fonte de energia na respiração celular. Além disso, fatores como a diluição dos ácidos orgânicos em consequência do aumento do tamanho da baga,

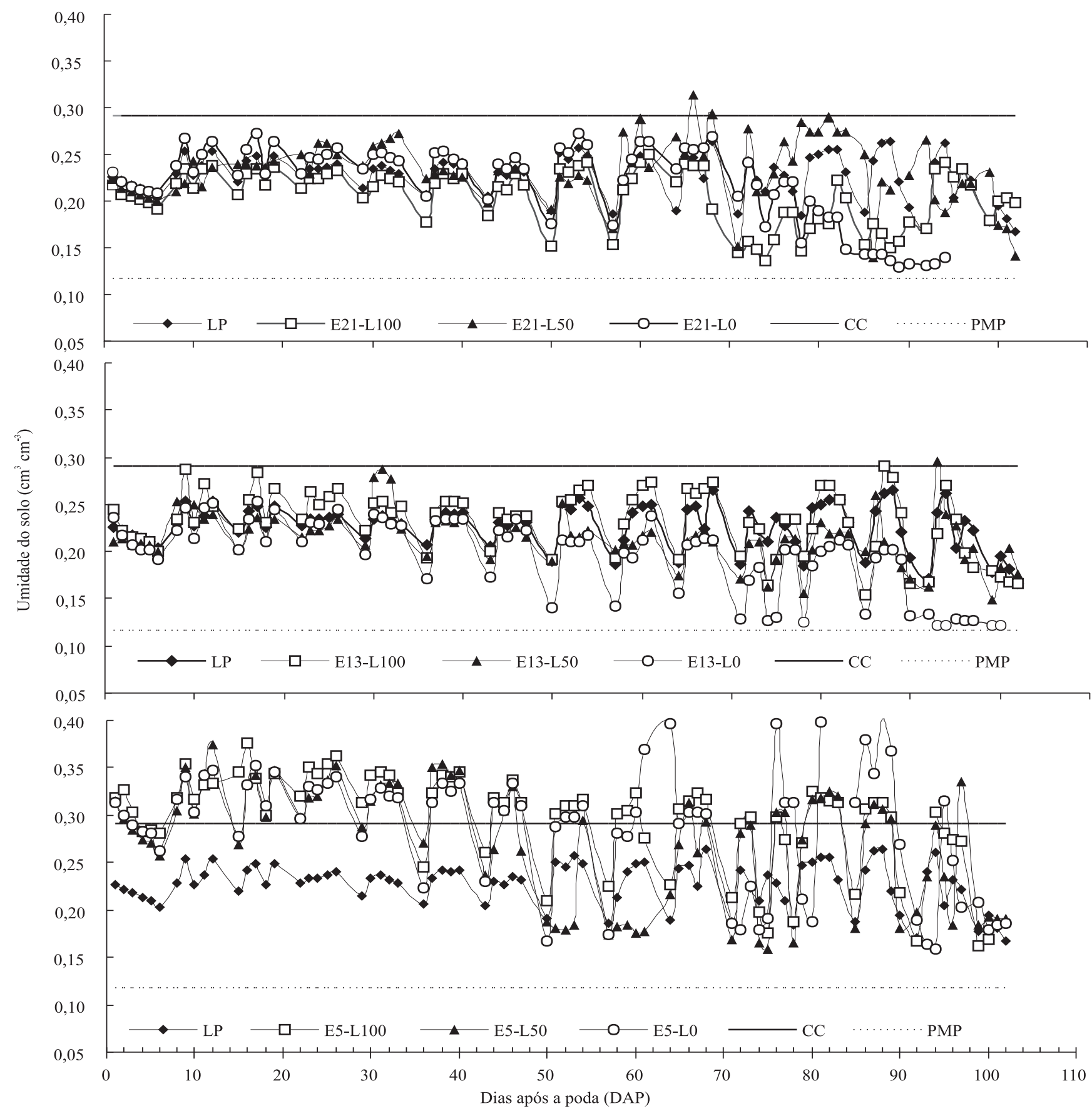

Figura 1. Umidade do solo na camada de $20 \mathrm{~cm}$, em função das épocas de alteração das lâminas de irrigação em relação à colheita e das lâminas de irrigação. LP, lâmina do produtor: irrigação com cerca de $95 \%$ da evapotranspiração da cultura (Etc), até um dia antes da colheita (E1-L95). E, épocas de alteração das lâminas de irrigação, em relação à colheita: E21, 21 dias, E13, 13 dias e E5, 5 dias antes da colheita. L, lâminas de irrigação aplicadas: L100, L50, e L0, lâminas a 100, 50 e 0\% da Etc, respectivamente; CC: capacidade de campo; PMP, ponto de murcha permanente. 
a migração de bases e a consequente salificação dos ácidos orgânicos também contribuem para a redução no teor de AT (Rizzon et al., 2000).

Os valores de SS/AT não apresentaram diferenças significativas, em função das épocas de alteração da irrigação e lâminas. Entretanto, observou-se diferença entre as médias e o tratamento controle (LP), pelo

Tabela 2. Fertilidade de gemas da cultivar de videira Superior Seedless, em função das épocas de alteração das lâminas de irrigação em relação à colheita e das lâminas de irrigação ${ }^{(1)}$.

\begin{tabular}{llllc} 
Época $^{(2)}$ & \multicolumn{4}{c}{ Lâminas de irrigação $(\% \mathrm{Etc})^{(3)}$} \\
\cline { 2 - 5 } & L0 & L50 & L100 & Média \\
\hline E5 & $20,6 \mathrm{aA}$ & $17,1 \mathrm{aA}$ & $20,8 \mathrm{aA}$ & 19,5 \\
E13 & $19,9 \mathrm{aA}$ & $18,2 \mathrm{aA}$ & $20,0 \mathrm{aA}$ & 19,4 \\
E21 & $19,9 \mathrm{aA}$ & $16,4 \mathrm{aA}$ & $18,3 \mathrm{aA}$ & 18,2 \\
\hline Média & 20,1 & 17,5 & 19,7 & - \\
\hline LP & $13,8^{* *}$ & - & - & - \\
\hline
\end{tabular}

${ }^{(1)}$ Médias seguidas de letras iguais, maiúsculas nas colunas e minúsculas nas linhas, não diferem entre si pelo teste de Ducan, a 5\% de probabilidade. **Média do tratamento LP em relação à média dos tratamentos significativa, pelo teste $\mathrm{F}$, a $1 \%$ de probabilidade. ${ }^{(2)}$ Épocas de alteração da lâmina de irrigação em relação à colheita: E5, 5 dias; E13, 13 dias e E21, 21dias antes da colheita. ${ }^{(3)}$ L0, L50 e L100, lâminas de irrigação a 0, 50 e $100 \%$ da evapotranspiração da cultura (Etc), respectivamente; LP, lâmina do produtor: irrigação com cerca de 95\% da Etc, até um dia antes da colheita (E1-L95). teste F, dois dias antes da colheita (Tabela 3). Ao se considerarem as datas de amostragem, percebe-se que a relação SS/AT teve semelhança com a evolução do teor de SS, com baixos valores no início da maturação e aumento progressivo até o período próximo à colheita. Resultados semelhantes da evolução de SS/AT foram encontrados por Sato et al. (2009), em estudo sobre a evolução da maturação e as características físico-químicas da uva 'Isabel' sobre diferentes porta-enxertos, na região norte do Paraná.

Para diâmetro de baga, peso médio, número médio de cachos e peso total de cachos por planta e produtividade, não houve diferença significativa, pelo teste $F$, entre os tratamentos e o tratamento controle (LP). O uso de diferentes épocas e lâminas poderá ser adotado pelo produtor, sem efeitos negativos no manejo da irrigação, sempre com vistas à economia de água. Assim, para estes atributos de produção, foram comparadas apenas as médias dos tratamentos (Tabela 5). O diâmetro das bagas e o peso médio do cacho por planta não diferiram significativamente, a 5\% de probabilidade, em função das épocas, lâminas e interação entre os fatores. Todos os valores obtidos de diâmetro de bagas e peso médio de cacho por planta foram superiores ao padrão

Tabela 3. Evolução de sólidos solúveis (SS, ${ }^{\circ}$ Brix), acidez titulável (AT, g de ácido tartárico por 100 mL de suco) e relação SS/AT, da cultivar de videira Superior Seedless, em função das épocas de alteração das lâminas de irrigação em relação à colheita e das lâminas de irrigação, aos 14, 9, 5 e 2 dias antes da colheita ${ }^{(1)}$.

\begin{tabular}{|c|c|c|c|c|c|c|c|c|c|}
\hline \multirow[t]{3}{*}{ Época ${ }^{(2)}$} & \multicolumn{9}{|c|}{ Lâminas de irrigação (\% da Etc) $)^{(3)}$} \\
\hline & L0 & L50 & L100 & L0 & L50 & L100 & L0 & L50 & L100 \\
\hline & \multicolumn{3}{|c|}{ SS } & \multicolumn{3}{|c|}{ AT } & \multicolumn{3}{|c|}{ SS/AT } \\
\hline & & & & & 14 dias & & & & \\
\hline E5 & $14,5 \mathrm{aA}$ & $13,6 \mathrm{aA}$ & $13,1 \mathrm{aA}$ & $0,5 \mathrm{aA}$ & $0,5 \mathrm{aA}$ & $0,5 \mathrm{aA}$ & $27,0 \mathrm{aA}$ & $27,7 \mathrm{aA}$ & $25,1 \mathrm{aA}$ \\
\hline E13 & $14,6 \mathrm{aA}$ & $14,6 \mathrm{aA}$ & $14,2 \mathrm{aA}$ & $0,5 \mathrm{aA}$ & $0,5 \mathrm{aA}$ & $0,6 \mathrm{aA}$ & $26,5 \mathrm{aA}$ & $26,6 \mathrm{aA}$ & $25,0 \mathrm{aA}$ \\
\hline E21 & $14,0 \mathrm{aA}$ & $13,8 \mathrm{aA}$ & $13,8 \mathrm{aA}$ & $0,5 \mathrm{aA}$ & $0,5 \mathrm{aA}$ & $0,5 \mathrm{aA}$ & $25,4 \mathrm{aA}$ & $25,3 \mathrm{aA}$ & $25,4 \mathrm{aA}$ \\
\hline \multirow[t]{2}{*}{ LP } & & $13,4^{\mathrm{ns}}$ & & & $0,7^{\mathrm{ns}}$ & & & $20,7^{\mathrm{ns}}$ & \\
\hline & & & & & 9 dias & & & & \\
\hline E5 & $16,8 \mathrm{aA}$ & $15,6 \mathrm{aA}$ & $15,8 \mathrm{aA}$ & $0,4 \mathrm{aA}$ & $0,5 \mathrm{aA}$ & $0,4 \mathrm{aA}$ & $40,5 \mathrm{aA}$ & $33,8 \mathrm{aA}$ & $37,2 \mathrm{aA}$ \\
\hline E13 & $15,6 \mathrm{aA}$ & $16,3 \mathrm{aA}$ & $15,9 \mathrm{aA}$ & $0,3 \mathrm{aA}$ & $0,4 \mathrm{aA}$ & $0,4 \mathrm{aA}$ & $40,6 \mathrm{aA}$ & $41,4 \mathrm{aA}$ & $36,6 \mathrm{aA}$ \\
\hline E21 & $15,3 \mathrm{aA}$ & $15,2 \mathrm{aA}$ & $15,3 \mathrm{aA}$ & $0,4 \mathrm{aA}$ & $0,4 \mathrm{aA}$ & $0,5 \mathrm{aA}$ & $37,6 \mathrm{aA}$ & $39,5 \mathrm{aA}$ & $33,7 \mathrm{aA}$ \\
\hline \multirow[t]{2}{*}{$\underline{\mathrm{LP}}$} & & $14,4^{\mathrm{ns}}$ & & & $0,4^{\mathrm{ns}}$ & & & $27,1^{\mathrm{ns}}$ & \\
\hline & & & & & 5 dias & & & & \\
\hline E5 & $16,6 \mathrm{aA}$ & $15,9 \mathrm{aA}$ & $15,8 \mathrm{aA}$ & $0,4 \mathrm{aA}$ & $0,5 \mathrm{aA}$ & $0,4 \mathrm{aA}$ & $38,3 \mathrm{aA}$ & $35,0 \mathrm{aA}$ & $35,0 \mathrm{aA}$ \\
\hline E13 & $15,8 \mathrm{aA}$ & $16,0 \mathrm{aA}$ & $15,9 \mathrm{aA}$ & $0,4 \mathrm{aA}$ & $0,5 \mathrm{aA}$ & $0,4 \mathrm{aA}$ & $36,7 \mathrm{aA}$ & $35,1 \mathrm{aA}$ & $35,1 \mathrm{aA}$ \\
\hline E21 & $15,2 \mathrm{aA}$ & $15,0 \mathrm{aA}$ & $15,2 \mathrm{aA}$ & $0,4 \mathrm{aA}$ & $0,4 \mathrm{aA}$ & $0,4 \mathrm{aA}$ & $33,7 \mathrm{aA}$ & $33,3 \mathrm{aA}$ & $34,3 \mathrm{aA}$ \\
\hline \multirow[t]{2}{*}{$\underline{\mathrm{LP}}$} & & $16,3^{\mathrm{ns}}$ & & & $0,4^{\mathrm{ns}}$ & & & $38,0^{\mathrm{ns}}$ & \\
\hline & & & & & 2 dias & & & & \\
\hline E5 & $16,8 \mathrm{aA}$ & $15,6 \mathrm{abA}$ & $15,8 \mathrm{aA}$ & $0,4 \mathrm{aB}$ & $0,5 \mathrm{bA}$ & $0,4 \mathrm{aA}$ & $40,5 \mathrm{bB}$ & $33,8 \mathrm{bA}$ & $37,3 \mathrm{aA}$ \\
\hline E13 & $15,7 \mathrm{aA}$ & $16,4 \mathrm{aA}$ & $15,9 \mathrm{aA}$ & $0,4 \mathrm{aB}$ & $0,4 \mathrm{aA}$ & $0,4 \mathrm{aA}$ & $40,6 \mathrm{aB}$ & $41,4 \mathrm{aA}$ & $36,6 \mathrm{aA}$ \\
\hline E21 & $15,3 \mathrm{aA}$ & $15,2 \mathrm{aA}$ & $15,3 \mathrm{aA}$ & $0,4 \mathrm{aA}$ & $0,4 \mathrm{aA}$ & $0,5 \mathrm{aA}$ & $37,6 \mathrm{aA}$ & $39,5 \mathrm{aA}$ & $33,7 \mathrm{aA}$ \\
\hline LP & & $16,1^{\mathrm{ns}}$ & & & $0,4^{\mathrm{ns}}$ & & & $36,6 * *$ & \\
\hline
\end{tabular}

${ }^{(1)}$ Médias seguidas de letras iguais, maiúsculas nas colunas e minúsculas nas linhas, não diferem entre si pelo teste de Ducan, a $5 \%$ de probabilidade. ${ }^{n s}$ e **Média do tratamento LP em relação à média dos tratamentos não significativa e significativa, respectivamente, pelo teste $\mathrm{F}$, a $1 \%$ de probabilidade. ${ }^{(2)}$ Épocas de alteração das lâminas de irrigação em relação à colheita: E5, 5 dias; E13, 13 dias e E21, 21 dias antes da colheita; (3)L0, L50 e L100, lâminas de irrigação a 0, 50 e 100\% da evapotranspiração da cultura (Etc), respectivamente; LP, lâmina do produtor: irrigação com cerca de 95\% da Etc, até um dia antes da colheita (E1-L95). 
mínimo, exigido pelo mercado externo para uva sem semente, que é de $19 \mathrm{~mm}$ e de $250 \mathrm{~g}$ (Brazilian Grapes Marketing Association, 1999). Resultados semelhantes de peso médio de cacho de uva 'Superior Seedless' variaram de 370 a $490 \mathrm{~g}$, em regime de deficit hídrico aplicado ao longo do ciclo fenológico, na Argentina

Tabela 4. Sólidos solúveis (SS, ${ }^{\circ}$ Brix), acidez titulável (AT, g ácido tartárico por $100 \mathrm{~mL}$ de suco) e relação SS/AT da cultivar de videira Superior Seedless, aos 14, 9, 5 e 2 dias antes da colheita ${ }^{(1)}$.

\begin{tabular}{cccc}
\hline Época (dias) & SS & AT & SS/AT \\
\hline 14 & $13,4 \mathrm{c}$ & $0,6 \mathrm{a}$ & $20,6 \mathrm{~d}$ \\
9 & $14,1 \mathrm{~b}$ & $0,5 \mathrm{~b}$ & $26,1 \mathrm{c}$ \\
5 & $15,8 \mathrm{a}$ & $0,4 \mathrm{c}$ & $35,4 \mathrm{~b}$ \\
2 & $15,8 \mathrm{a}$ & $0,4 \mathrm{~d}$ & $37,8 \mathrm{a}$ \\
\hline
\end{tabular}

${ }^{(1)}$ Médias seguidas de letras iguais, nas colunas não diferem entre si pelo teste de Duncan, a 5\% de probabilidade.

Tabela 5. Número de cachos por planta, peso total de cachos por planta, produtividade e eficiência de uso de água da cultivar de videira Superior Seedless, em função das épocas de alteração das lâminas de irrigação em relação à colheita $\mathrm{e}$ das lâminas de irrigação ${ }^{(1)}$.

\begin{tabular}{|c|c|c|c|c|}
\hline \multirow[t]{2}{*}{ Época ${ }^{(2)}$} & \multicolumn{4}{|c|}{ Lâminas de irrigação $(\% \text { Etc })^{(3)}$} \\
\hline & L0 & L50 & L100 & Média \\
\hline & \multicolumn{4}{|c|}{ Número médio de cachos por planta } \\
\hline E5 & $28,7 \mathrm{bA}$ & $30,9 \mathrm{abA}$ & $37,6 \mathrm{aA}$ & 32,4 \\
\hline E13 & $35,7 \mathrm{aA}$ & $33,7 \mathrm{aA}$ & $34,1 \mathrm{aA}$ & 34,5 \\
\hline E21 & $32,1 \mathrm{aA}$ & $32,9 \mathrm{aA}$ & $32,4 \mathrm{aA}$ & 32,4 \\
\hline Média & 32,2 & 32,5 & 34,7 & - \\
\hline \multirow[t]{2}{*}{ LP } & - & - & - & $32,2^{\text {ns }}$ \\
\hline & \multicolumn{4}{|c|}{ Peso total de cachos por planta (kg por planta) } \\
\hline E5 & $17,3 \mathrm{bA}$ & $19,6 \mathrm{abA}$ & $24,4 \mathrm{aA}$ & 20,4 \\
\hline E13 & $23,8 \mathrm{aA}$ & $21,9 \mathrm{aA}$ & $23,5 \mathrm{aA}$ & 23,0 \\
\hline E21 & $21,2 \mathrm{aA}$ & $21,3 \mathrm{aA}$ & $21,9 \mathrm{aA}$ & 21,5 \\
\hline Média & 20,8 & 20,9 & 23,3 & - \\
\hline \multirow[t]{2}{*}{$\underline{\mathrm{LP}}$} & - & - & - & $19,8^{\mathrm{ns}}$ \\
\hline & \multicolumn{4}{|c|}{ Produtividade $\left(\mathrm{Mg} \mathrm{ha}^{-1}\right)$} \\
\hline E5 & $24,7 \mathrm{bA}$ & $27,9 \mathrm{abA}$ & $34,9 \mathrm{aA}$ & 30,5 \\
\hline E13 & $33,9 \mathrm{aA}$ & $31,3 \mathrm{aA}$ & $33,5 \mathrm{aA}$ & 32,9 \\
\hline$\underline{E} 21$ & $30,3 \mathrm{aA}$ & $30,4 \mathrm{aA}$ & $31,3 \mathrm{aA}$ & 30,7 \\
\hline Média & 29,7 & 29,9 & 33,2 & - \\
\hline \multirow[t]{2}{*}{$\overline{L P}$} & - & - & - & $28,3^{\mathrm{ns}}$ \\
\hline & \multicolumn{4}{|c|}{ Eficiência de uso de água $\left(\mathrm{kg} \mathrm{m}^{-3}\right)$} \\
\hline E5 & $6,4 \mathrm{bB}$ & $6,9 \mathrm{bA}$ & $8,8 \mathrm{aA}$ & 7,3 \\
\hline E13 & $6,5 \mathrm{aB}$ & $8,1 \mathrm{aA}$ & $8,4 \mathrm{aA}$ & 7,7 \\
\hline$\underline{E} 21$ & $9,1 \mathrm{aA}$ & $8,3 \mathrm{aA}$ & $7,8 \mathrm{aA}$ & 8,4 \\
\hline Média & 7,31 & 7,8 & 8,3 & - \\
\hline LP & - & - & - & $7,2^{\mathrm{ns}}$ \\
\hline \multicolumn{5}{|c|}{$\begin{array}{l}{ }^{(1)} \text { Médias seguidas de letras iguais, maiúsculas nas colunas e minúsculas } \\
\text { nas linhas, não diferem entre si pelo teste de Ducan, } 5 \% \text { de probalidade. } \\
\text { ns Média do tratamento LP em relação à média dos tratamentos, não } \\
\text { significativa pelo teste F, a } 1 \% \text { de probabilidade. }{ }^{(2)} \text { Épocas de alteração } \\
\text { das lâminas de irrigação em relação à colheita: E5, } 5 \text { dias; E13, } 13 \text { dias } \\
\text { e E21, } 21 \text { dias antes da colheita; }{ }^{(3)} \text { L0, L50 e L100, lâminas de irrigação a } \\
0,50 \text { e } 100 \% \text { da evapotranspiração da cultura (Etc), respectivamente; LP, } \\
\text { lâmina do produtor: irrigação com cerca de } 95 \% \text { da Etc, até um dia antes } \\
\text { da colheita (E1-L95). }\end{array}$} \\
\hline
\end{tabular}

(Serman et al., 2004). O diâmetro de baga e o peso de cacho por planta, na fase de maturação da uva, mostraram-se pouco sensíveis ao deficit hídrico que pode ser adotado em estratégias de economia de água. Segundo Ferreyra et al. (2006), é importante detectar um período em que o deficit de irrigação é moderado, pois se sabe que a falta de água, durante o crescimento da uva mesa, limita a produção e a qualidade da fruta, particularmente se o deficit hídrico se iniciar entre a floração e a pinta.

Houve interação entre as épocas e lâminas quanto ao número médio de cachos e peso total de cachos por planta, produtividade e eficiência de uso de água (Tabela 5). Verifica-se que, apenas para a época E5, a lâmina L100 apresentou maior número de cachos e peso total de cachos por planta que a L0, não tendo diferido da lâmina L50. Nas demais épocas (E13 e E21), não houve diferença estatística para o número médio de cachos e peso total de cachos por planta, tendo-se obtido uma economia de água de $53,38 \mathrm{~mm}$, quando a irrigação foi suspensa 21 dias antes da colheita. Todavia, as diferenças estatísticas do presente trabalho devem-se também ao raleio das bagas das uvas - efetuado de maneira irregular entre as plantas no Submédio do Vale do São Francisco -, visto que não houve diferença estatística na fertilidade de gemas (Tabela 2), nem no peso médio de cachos por planta, pois, na fase de maturação, o número de cachos não se altera mais. Menores valores de número de cachos e peso total de cachos da cultivar Itália, para os tratamentos que obtiveram a irrigação suspensa aos 16 DAC e influência do raleio das bagas nestes parâmetros, foram observadas por Bassoi et al. (1999), no Submédio do Vale do São Francisco. O número médio de cachos obtido por planta não apresentou diferenças significativas nos tratamentos com deficits hídricos, nas diferentes fases de cultivo, em comparação ao tratamento com irrigação plena, em videira 'Sultanina', no Sul da África (Myburgh, 2003), provavelmente por não se realizar o raleio de bagas nessa região.

Ao se considerarem as lâminas de irrigação, observa-se que apenas a época E5 apresentou diferenças significativas quanto à produtividade (Tabela 5). Quando aplicada a lâmina L100, as videiras apresentaram, estatisticamente, maior valor (34,9 $\mathrm{Mg} \mathrm{ha}^{-1}$ ) que L0. Valores de produtividade semelhantes foram observados por Serman et al. (2004), em estudo realizado para avaliar o efeito do 
deficit hídrico na 'Superior Seedless', em que obtiveram produtividade entre 20,53 e $25,21 \mathrm{Mg} \mathrm{ha}^{-1}$.

As diferenças de produtividade também estão relacionadas ao número de cachos por planta e, consequentemente, ao peso total de cachos por planta. Essas respostas, de alguma maneira, podem ter sido ocasionadas pelo raleio das bagas e pelo manejo da videira, realizado no ano anterior, uma vez que a alteração das lâminas de irrigação ocorreu apenas na fase de maturação da uva. Porém, a falta de diferenças significativas de produtividade, para as épocas E13 e E21, pode ser resultado da regulação da perda de água por transpiração, principalmente nas horas de maior demanda, conforme Ferreyra et al. (2006). Isto pode levar mais de cinco dias para acontecer e, por isso, as plantas que tiveram 13 e 21 dias conseguiram evitar perdas evapotranspirométricas e não tiveram perdas significativas de produtividade. Segundo Bidin et al. (2005), as plantas sujeitas a deficit de água no solo, em comparação às plantas sob irrigação plena, realizaram ajustes na taxa de transpiração para minimizar as respostas ao estresse, tendo-se verificado um decréscimo na taxa de transpiração 14 dias após o início do experimento. Pode-se observar que, para a época E5, a lâmina L100 apresentou os maiores valores de eficiência de uso de água (EUA), e que a lâmina L50 igualou-se estatisticamente à L0, com os menores valores (Tabela 5). Para a lâmina L0, a época E21 teve as melhores médias de EUA, tendo diferido de E5 e E13. Vale salientar que estes valores foram obtidos considerando-se apenas uma safra por ano. Os valores de EUA, obtidos neste trabalho, são superiores aos encontrados por Serman et al. (2004), que trabalharam com diferentes lâminas de irrigação na videira 'Superior Seedless' e obtiveram valores de EUA entre 2,62 a $3,16 \mathrm{~kg} \mathrm{~m}^{-3}$, todavia, na região de estudos desses autores, a duração do ciclo fenológico é maior que no Submédio do Vale do São Francisco.

Os resultados dos atributos de qualidade da uva, obtidos na pós-colheita, podem ser observados na Tabela 6. Houve diferença estatística, pelo teste Duncan $(\mathrm{p}<0,05)$, quanto à firmeza da baga da uva pós-colheita, em função da época e das lâminas, o que não foi observado entre as médias dos tratamentos e o tratamento LP. Ao se considerar a época de alteração, nota-se que houve diferença de firmeza apenas quando utilizada a lâmina L0, tendo-se alcançado os melhores resultados na E21. Não houve diferença significativa entre as diferentes lâminas nas épocas E13 e E5. Esta resposta é altamente desejável pois a firmeza ou turgidez da baga é um atributo físico bastante importante para avaliar a qualidade da uva na pós-colheita, por permitir maior resistência ao transporte e conservação em câmara fria.

Não houve diferença estatística no teor de SS, na pós-colheita em função das épocas e lâminas de irrigação, nem entre as médias dos tratamentos e o tratamento LP (Tabela 6), o que pode indicar uma das estratégias de manejo a ser adotada pelo produtor para economizar água, sem impactos negativos nos SS. Resultados semelhantes foram encontrados por Shellie et al. (2006), em dois anos de produção (2003 e 2004). Entretanto, estes autores observaram, no ano de 2002, no sudeste de Idaho, que as concentrações de SS foram levemente maiores nas plantas sob irrigação com 35 ou $35-70 \%$ da ETc (iniciada com a frutificação até duas semanas depois da colheita). No presente trabalho, os valores médios de SS oscilaram entre $15,2^{\circ}$ Brix e $16,8^{\circ} \mathrm{Brix}$. Estes resultados foram semelhantes ao valor

Tabela 6. Atributos físico-químicos da cultivar de videira Superior Seedless, na pós-colheita, em função das épocas de alteração das lâminas de irrigação em relação à colheita e das lâminas de irrigação ${ }^{(1)}$.

\begin{tabular}{|c|c|c|c|c|}
\hline \multirow[t]{2}{*}{ Época $^{(2)}$} & \multicolumn{4}{|c|}{ Lâminas de irrigação $(\% \mathrm{Etc})^{(3)}$} \\
\hline & L0 & L50 & L100 & Média \\
\hline & \multicolumn{4}{|c|}{ Firmeza de bagas (Newton) } \\
\hline E5 & $7,0 \mathrm{aB}$ & $6,9 \mathrm{aA}$ & $6,8 \mathrm{aA}$ & - \\
\hline E13 & $7,4 \mathrm{aB}$ & $7,3 \mathrm{aA}$ & $7,1 \mathrm{aA}$ & - \\
\hline E21 & $9,2 \mathrm{aA}$ & 7,7abA & $7,2 \mathrm{bA}$ & - \\
\hline \multirow[t]{2}{*}{ LP } & - & - & - & $7,4^{\mathrm{ns}}$ \\
\hline & \multicolumn{4}{|c|}{ SS $\left({ }^{\circ}\right.$ Brix $)$} \\
\hline E5 & $16,8 \mathrm{aA}$ & $15,6 \mathrm{aA}$ & $15,8 \mathrm{aA}$ & - \\
\hline E13 & $15,7 \mathrm{aA}$ & $16,4 \mathrm{aA}$ & $15,9 \mathrm{aA}$ & - \\
\hline E21 & $15,3 \mathrm{aA}$ & $15,2 \mathrm{aA}$ & $15,3 \mathrm{aA}$ & \\
\hline \multirow[t]{2}{*}{ LP } & - & - & - & $16,0^{\mathrm{ns}}$ \\
\hline & \multicolumn{4}{|c|}{ AT (g ácido tartárico por $100 \mathrm{~mL}$ de suco) } \\
\hline E5 & $0,45 \mathrm{aA}$ & $0,50 \mathrm{aA}$ & $0,45 \mathrm{aA}$ & 30,5 \\
\hline E13 & $0,37 \mathrm{aB}$ & $0,40 \mathrm{aB}$ & $0,42 \mathrm{aA}$ & 32,9 \\
\hline E21 & $0,40 \mathrm{bB}$ & $0,40 \mathrm{bB}$ & $0,47 \mathrm{aA}$ & 30,7 \\
\hline \multirow[t]{2}{*}{ LP } & - & - & - & $0,4^{\text {ns }}$ \\
\hline & \multicolumn{4}{|c|}{ SS/AT } \\
\hline E5 & $40,5 \mathrm{aA}$ & $33,8 \mathrm{aB}$ & $37,6 \mathrm{aA}$ & - \\
\hline E13 & $40,6 \mathrm{aA}$ & $41,4 \mathrm{aA}$ & $36,6 \mathrm{aA}$ & - \\
\hline E21 & $37,6 \mathrm{aA}$ & $39,5 \mathrm{aA}$ & $33,7 \mathrm{aA}$ & - \\
\hline LP & - & - & - & $36,6^{\text {ns }}$ \\
\hline
\end{tabular}

${ }^{(1)}$ Médias seguidas de letras iguais, maiúsculas nas colunas e minúsculas nas linhas, não diferem entre si pelo teste de Ducan, a 5\% de probalidade. ${ }^{n}$ Média do tratamento $\mathrm{LP}$ em relação à média dos tratamentos não significativa pelo teste $\mathrm{F}$, a $1 \%$ de probabilidade ${ }^{(2)}$ Épocas de alteração das lâminas de irrigação em relação à colheita: E5, 5 dias; E13, 13 dias e E21, 21dias antes da colheita. ${ }^{(3)}$ L0, L50 e L100, lâminas de irrigação a 0,50 e $100 \%$ da evapotranspiração da cultura (Etc); LP, lâmina do produtor: irrigação com cerca de $95 \%$ da Etc, até um dia antes da colheita (E1-L95). 
encontrado $\left(17,3^{\circ}\right.$ Brix $)$ por Grangeiro et al. (2002), que trabalharam com a cultivar Superior Seedless no Submédio do Vale do São Francisco, sem condição de supressão da irrigação. Valores inferiores de SS foram observados para esta mesma cultivar, sob deficit hídrico, na Argentina (Serman et al., 2004), e para cultivar Itália no Submédio do Vale do São Francisco (Bassoi et al., 1999).

Diferenças significativas na AT, na pós-colheita, foram observadas em função dos fatores épocas e lâminas de irrigação, sem diferenças entre as médias dos tratamentos e o tratamento LP (Tabela 6). Ao se considerar a época de diferenciação da irrigação em relação à colheita, houve diferenças nos valores de AT quando foram utilizadas as lâminas L0 e L50, tendo-se obtido maior AT com essas lâminas na época E5. Quanto às lâminas de irrigação, verifica-se que apenas a E21 apresentou diferenças estatísticas, com os menores valores de AT para L0 e L50. Estes resultados indicam que quanto maior o deficit de irrigação e a sua duração, maior a redução de acidez titulável na uva 'Superior Seedless'. Redução aparente de AT também foi observada em videiras 'Merlot' submetidas a deficit de irrigação, no sudeste de Idaho (Shellie et al., 2006). Essa redução da acidez titulável, associada ao deficit hídrico, pode ser atribuída à redução de malato (Matthews \& Anderson, 1988; Esteban et al., 1999).

Para a relação SS/AT, na pós-colheita, constatouse que houve diferença estatística apenas para L50, com os maiores valores na E13 e E21 (Tabela 6). Entretanto, todas as médias dos tratamentos e do tratamento LP apresentaram valores acima de 20:1, limite desejável para a exportação (Beinroth, 1993; Choudhury, 2000). Sabe-se que a relação SS/AT é um importante atributo qualitativo, por indicar o sabor do produto, o qual é resultado da contribuição dos componentes responsáveis pela acidez e doçura (Mattiuz, 2002).

\section{Conclusões}

1. As épocas de alteração das lâminas de irrigação, em relação à colheita e as lâminas de irrigação não afetam o diâmetro de bagas e o peso médio de cachos por planta.

2. Lâminas de irrigação têm efeitos diferentes sobre o número e o peso total de cachos por planta, produtividade e eficiência de uso de água da uva
'Superior Seedless', apenas aos cinco dias antes da colheita.

3. Há influência das épocas de alteração da irrigação e lâminas de irrigação sobre a firmeza das bagas, a acidez titulável e a relação entre sólidos solúveis e acidez titulável.

4. A redução das lâminas, na fase de maturação da uva 'Superior Seedless', beneficia a qualidade da uva no Submédio do Vale do São Francisco.

5. A estratégia de deficit hídrico, na fase de maturação da uva 'Superior Seedless' aos 13 ou aos 21 dias antes da colheita, permite produtividade, qualidade da uva e eficiência de uso de água semelhante ao do manejo adotado pelo produtor.

\section{Agradecimentos}

À Universidade Federal Rural de Pernambuco e à Embrapa Semiárido, pelo apoio técnico-científico e financeiro; à Coordenação de Aperfeiçoamento de Pessoal de Nível Superior, pela concessão de bolsa; e à Fazenda Agrobrás, pelo apoio técnico.

\section{Referências}

ALLEN, R.G.; PEREIRA, L.S.; RAES, D.; SMITH, M. Crop evapotranspiration: guidelines for computing crop water requirements. Rome: FAO, 1998. 310p. (Irrigation and drainage paper, 56).

ÁVILANETTO, J.; AZEVEDO, P.V. de; SILVA, B.B. da; SOARES, J.M.; TEIXEIRA, A.H. de C. Exigência hídrica da videira na Região do Submédio São Francisco. Pesquisa Agropecuária Brasileira, v.35, p.1559-1566, 2000.

BASSOI, L.H.; ASSIS, J.S. de; LIMA FILHO, J.M.P.; RIBEIRO, H.A.; SILVA, M.R.; MIRANDA, A.A. Interrupção da irrigação no período de maturação da uva cv. Itália. Petrolina: Embrapa-CPATSA, 1999. 5p. (Embrapa-CPATSA. Comunicado técnico, 79).

BEINROTH, E.W. Determinação do ponto de colheita. In: GORGAATI NETO, A.; GAYET, J.P.; BEINROTH, E.W. (Ed.). Uva para exportação: procedimentos de colheita e pós-colheita. Brasília: Embrapa-SPI: Frupex, 1993.p.20-21.(Frupex. Publicações técnicas, 2).

BIDIN, M.; BELLESI, S.; ORLANDINI, S.; FIBBI, L.; MORIONDO, M.; SINCLAIR, T. Influence of water deficit stress on leaf area development and transpiration of Sangiovese grapevines grown in pots. American Journal of Enology and Viticulture, v.56, p.68-72, 2005.

BRAZILIAN GRAPES MARKETING ASSOCIATION. Instrutivo: controle de qualidade: safra II/99. Petrolina: BGMA, 1999. Paginação irregular. 
CHITARRA, M.I.F.; CHITARRA, A.B. Pós-colheita de frutos e hortaliças: fisiologia e manuseio. Lavras: ESAL: FAEPE, 1990. 320p.

CHOUDHURY, M.M. Colheita, manuseio pós-colheita e qualidade mercadológica de uvas de mesa. In: LEÃO, P.C. de S.; SOARES, J.M. (Ed.). A viticultura no Semi-Árido brasileiro. Petrolina: Embrapa Semiárido, 2000. p.347-368.

DOORENBOS, J.; KASSAM, A.H. Efeito da água no rendimento das culturas. Campina Grande: UFPB, 1994. 306p. (FAO. Estudo FAO. Irrigação e drenagem, 33).

EMBRAPA SEMIÁRIDO. Registro de observações meteorológicas. Petrolina: Embrapa Semiárido. Disponível em: $<$ http://www.cpatsa.embrapa.br:8080/servicos/dadosmet/estacoes/ bebnovembro.html>. Acesso em: 24 out. 2007.

ESTEBAN, M.A.; VILLANUEVA, M.J.; LISSARRAGUE, J.R. Effect of irrigation on changes in berry composition of Tempranillo during maturation. Sugars, organic acids, and mineral elements. American Journal of Enology and Viticulture, v.50, p.418-434, 1999.

FERREYRA, R.E.; SELLES, G.; SILVA, H.; AHUMADA, R.; MUÑOZ, I.; MUÑOZ, V. Efecto del água aplicada em las relaciones hídricas y productividad de la vid 'Crimson Seedless'. Pesquisa Agropecuária Brasileira, v.41, p.1109-1118, 2006.

GRANGEIRO, L.C.; LEAO, P.C. de S.; SOARES, J.M. Caracterização fenológica e produtiva da variedade de uva Superior Seedless cultivada no Vale do São Francisco. Revista Brasileira de Fruticultura, v.24, p.552-554, 2002.

HARGREAVES, G.H. Climate zoning for agricultural production in Northeast Brazil. Logan: Utah State University, 1974. 6p.

KARMELI, D.; KELLER, J. Trickle irrigation design. California: Rain Bird Sprinkler Manufacturing Corporation, 1975. 133p.

LEÃO, P.C. de S.; SILVA, E.E.G. da. Caracterização fenológica e requerimentos térmicos de variedades de uvas sem sementes no vale do São Francisco. Revista Brasileira de Fruticultura, v.25, p.379-382, 2003.

MARINHO, L.B. Deficit hídrico regulado na fase de maturação da uva "Superior Seedless" na região do Submédio São Francisco. 2008. 106p. Dissertação (Mestrado) - Universidade Federal Rural de Pernambuco, Recife.

MATTHEWS, M.A.; ANDERSON, M.M. Fruit ripening in Vitis vinifera L.: responses to seasonal water deficits. American Journal of Enology and Viticulture, v.39, p.313-320, 1988.

MATTIUZ, B.-H. Efeitos de injúrias mecânicas e do processamento mínimo na fisiologia pós-colheita de goiabas. 2002. 120p. Tese (Doutorado) - Universidade Estadual Paulista, Jaboticabal.
MATTIUZ, B.-H.; MIGUEL, A.C.A.; NACHTIGAL, J.C.; DURIGAN, J.F.; CAMARGO, U.A. Processamento mínimo de uvas de mesa sem semente. Revista Brasileira de Fruticultura, v.26, p.226-229, 2004.

MYBURGH, P.A. Responses of Vitis vinifera L. cv. Sultanina to water deficits during various pré- and post-harvest phases under semi-arid conditions. South African Journal of Enology and Viticulture, v.24, p.25-33, 2003.

NETZER, Y.; YAO, C.; SHENKER, M. Water use and the development of seasonal crop coefficients for Superior Seedless grapevines trained to an open-gable trellis system. Irrigation Science, v.27, p.109-120, 2009.

PREGNOLATTO, W.; PREGNOLATTO, N.P. (Coord.). Normas analíticas do Instituto Adolfo Lutz: métodos químicos e físicos para análise dos alimentos. 3.ed. São Paulo: Instituto Adolfo Lutz, 1985. 533p.

REEDY, S.J.; AMORIM NETO, M. da S. Dados de precipitação, evapotranspiração potencial, radiação solar global de alguns locais e classificação climática do Nordeste do Brasil. Petrolina: Embrapa- CPATSA, 1993. 280p.

RIZZON, L.A.; MIELE, A.; MENEGUZZO, J. Avaliação da uva cv. Isabel para elaboração de vinho tinto. Ciência e Tecnologia de Alimentos, v.20, p.115-121, 2000.

SAS INSTITUTE. SAS user's guide. Version 9.0. Cary: SAS Institute, 2002.

SATO, A.J.; SILVA, B.J. da; BERTOLUCCI, R.; CARIELO, M.; GUIRAUD, M.C.; FONSECA, I.C. de B.; ROBERTO, S.R. Evolução da maturação e características fisico-químicas de uvas da cultivar Isabel sobre diferentes porta-enxertos na Região Norte do Paraná. Semina: Ciências Agrárias, v.30, p.11-20, 2009.

SERMAN, F.V.; LIOTTA, M.; PARERA, C. Effects of irrigation deficit on Table grape cv. Superior Seedless production. Acta Horticulturae, n.646, p.183-186, 2004.

SHELLIE, K.C. Vine and berry response of Merlot (Vitis vinifera L.) to differential water stress. American Journal of Enology and Viticulture, v.57, p.514-518, 2006.

SOARES, J.M.; COSTA, F.F. da. Irrigação da cultura da videira. In: LEÃO, P.C. de S.; SOARES, J.M. (Org.). A viticultura no Semi-Árido brasileiro. Petrolina: Embrapa Semiárido, 2000. p.147-212.

YASSIN, N.; MORAIS, A.R. de; MUNIZ, J.A. Análise de variância em um experimento fatorial de dois fatores com tratamentos adicionais. Ciência e Agrotecnologia, edição especial, p.1541-1547, 2002.

Recebido em 16 de setembro de 2009 e aprovado em 22 de novembro de 2009 